\title{
A FORMAÇÃO STRICTO SENSU DE PROFESSORES DA EDUCAÇÃO BÁSICA E A AUTONOMIA NO TRABALHO DOCENTE: RELAÇÕES POSSÍVEIS
}

\author{
Dayse Kelly Barreiros de OLIVEIRA ${ }^{1}$ \\ Ellen Michelle Barbosa de MOURA ${ }^{2}$ \\ Fernanda Bartoly Gonçalves de LIMA ${ }^{3}$
}

\begin{abstract}
Resumo
O artigo tem como objetivo analisar a formação stricto sensu e as possíveis relações com a constituição e desenvolvimento da autonomia dos professores que atuam na educação básica da rede pública do Distrito Federal. A partir disso, questiona-se: Qual seria a relação da formação stricto sensu com a constituição da autonomia no trabalho docente? Como os mestres e doutores, que atuam na educação básica, relacionam formação e autonomia no trabalho docente? De base qualitativa, a pesquisa utiliza como método de análise o materialismo histórico dialético e os procedimentos de coleta de dados foram a entrevista semiestruturada e questionário. É possível inferir, a partir das análises, que a formação stricto sensu é um potencializador do desenvolvimento da autonomia, pois possibilita que o professor tenha melhores condições de definir o que ensinar, como ensinar e por que ensinar, compreendendo sua função no processo de formação da humanidade nos indivíduos.
\end{abstract}

Palavras-chave: Docência na Educação Básica. Pesquisa Científica. Pós-Graduação.

\footnotetext{
${ }^{1}$ Doutora em Educação. Universidade de Brasília. ORCID 0000-0002-2686-8698.

E-mail: daysekb@gmail.com.

${ }^{2}$ Mestre em Educação. Secretaria de Estado de Educação do Distrito Federal. ORCID 0000-0001-6664-6419.

E-mail: ellenmou@gmail.com.

${ }^{3}$ Doutora em Educação. Instituto Federal de Brasília. ORCID 0000-0001-8425-1269.

E-mail: fernanda.lima@ifb.edu.br.
} 


\title{
THE STRICTO SENSU POSTGRADUATION OF BASIC EDUCATION TEACHERS AND THE AUTONOMY IN THE TEACHING WORK: POSSIBLE RELATIONSHIPS
}

Dayse Kelly Barreiros de OLIVEIRA

Ellen Michelle Barbosa de MOURA

Fernanda Bartoly Gonçalves de LIMA

\begin{abstract}
The article aims to analyze the stricto sensu postgraduation and the possible relationships with the autonomy constitution and capacity development of teachers working in basic education in the public schools of the Federal District. Based on that, the question arises: What would be the relationship between the stricto sensu postgraduation with the constitution of autonomy in teaching work? How do MSc and PhD teachers, who work in basic education, relate training and autonomy in teaching work? On a qualitative basis, the research uses as a method of analysis or historical dialectical materialism and the data collection procedures consisted of semi-structured interviews and questionnaires. It is possible to infer, from the analysis, that stricto sensu postgraduation is an enhancer of autonomy development, as the teacher may have better conditions to define what, how and why to teach, understanding their role in the process of building humanity in the individuals.
\end{abstract}

Keywords: Postgraduate Studies. Scientific Research. Teaching in Basic Education. 


\title{
LA FORMACIÓN STRICTO SENSU DEL PROFESORADO DE EDUCACIÓN BÁSICA Y AUTONOMÍA EN EL TRABAJO DOCENTE: POSIBLES RELACIONES
}

\author{
Dayse Kelly Barreiros de OLIVEIRA \\ Ellen Michelle Barbosa de MOURA \\ Fernanda Bartoly Gonçalves de LIMA
}

\begin{abstract}
Resumen
El artículo tiene como objetivo analizar la formación stricto sensu y las posibles relaciones con la constitución y desarrollo de la autonomía de los docentes que laboran en la educación básica de la red pública del Distrito Federal. De ahí surge la pregunta: ¿Cuál sería la relación entre la formación stricto sensu y la constitución de la autonomía en la docencia? ¿Cómo los profesores con maestría y doctorado que trabajan en educación básica relacionan la formación y la autonomía en la labor docente? Sobre una base cualitativa, la investigación utiliza el materialismo histórico dialéctico como método de análisis y los procedimientos de recolección de datos fueron la entrevista semi estructurada y el cuestionario. Es posible inferir, del análisis, que la formación stricto sensu es un potencial para el desarrollo de la autonomía, ya que permite al docente tener mejores condiciones para definir qué enseñar, cómo enseñar y por qué enseñar, entendiendo su rol en el proceso de formación de la humanidad en individuos.
\end{abstract}

Palabras clave: Curso de Posgrado. Docencia en la Educación Básica. Investigación Científica. 


\section{Iniciando a temática}

Tratar sobre a autonomia na formação de professores é uma tarefa complexa, afinal ser um sujeito autônomo na escola não é somente um processo de conquista pessoal, mas também um processo de transformação, na medida em que novas práticas vão sendo implementadas e consolidadas. Segundo Contreras (2012) a autonomia, sempre vinculada à ideia de capacidade que demanda a consciência do coletivo, significa independência intelectual na perspectiva que permite ao sujeito a clareza para analisar os problemas, entendendo que, no seu espaço de trabalho, existem condicionantes decorrentes do sistema educacional e de sua organização. Entendemos a necessidade de o professor se constituir como um intelectual autônomo, que investiga, propõe e busca novas formas de agir numa ação coletiva e não de forma isolada.

Considerando essas possibilidades do ser professor, relacionando com o percurso formativo da formação de professores no Brasil, constata-se o crescimento da quantidade de professores de educação básica que buscam o processo de formação stricto sensu nos programas de pósgraduação. Atualmente, esse nível de ensino tem sido procurado como importante investimento da progressão na carreira e qualificação profissional de diferentes áreas, e está em constante crescimento. Dados que comprovam esse fator é que em um período de 42 anos, a pós-graduação stricto sensu brasileira passou de 699 cursos no ano de 1976, para mais de 4.264 programas em 2017, sendo 2.479 em instituições federais, 993 estaduais e 792 particulares, portanto, um crescimento considerável (BRASIL, 2018).

Apesar do crescimento apontado, existe, no contexto político atual, a clara tentativa de desmonte das universidades públicas, através de ações, tais como: discursos de pessoas ligadas ao governo acerca de possíveis prejuízos que o aumento do acesso ao ensino superior teria causado para o Brasil (CAMPOREZ, 2019); corte de verbas para os cursos de pós-graduação; fechamento dos editais de bolsas de estudos para a pesquisa, entre outros. Essas ações podem causar retrocessos, tanto na possibilidade de ingresso dos professores da educação básica na pós-graduação stricto sensu, quanto na realização de pesquisas.

A pós-graduação se destina aos egressos de diferentes graduações, e conta com duas modalidades: a lato sensu, que corresponde aos cursos de especialização, voltada para o aperfeiçoamento e qualificação do profissional; e a stricto sensu, com cursos voltados para pesquisa de uma determinada área, contribuindo para a formação científica e acadêmica, em que se encaixam os cursos de mestrado, com duração média de dois anos, e os de doutorado, com cerca de quatro anos. E é sobre essa segunda modalidade que esse estudo trata, pois entendemos a formação stricto 
sensu como uma opção de continuidade da formação superior. Além disso, levando em conta que o objeto do estudo envolve a educação básica, nos pautamos exclusivamente nos cursos de mestrado e doutorado em Educação.

Os mestrados e doutorados foram instituídos pelo Parecer nº 977/1965, o Parecer Sucupira (BRASIL, 1965), que conceitua a pós-graduação brasileira. Em fevereiro de 1969, foi aprovado o Parecer $\mathrm{n}^{0} 77$ regulamentando sua implantação. No final de 1965, foi aprovado o primeiro mestrado na área de educação e ensino, na Pontifícia Universidade Católica do Rio de Janeiro (PUC-Rio) ${ }^{4}$. Na atualidade, têm-se 178 programas em educação reconhecidos (132 acadêmicos e 46 profissionais), desses 67\% de instituições públicas (BRASIL, 2017).

Em consonância ao exposto, percebemos a pós-graduação em educação e ensino se expandindo cada vez mais e, consequentemente, se constituindo como uma opção de formação continuada dos professores da educação básica, pois de acordo com o Relatório do $2^{\circ}$ Ciclo de Monitoramento das metas do Plano Nacional de Educação somente 2,4\% dos professores da educação básica têm formação no mestrado e 0,4\% de doutorado (BRASIL, 2018, p. 280).

Diante disso, o objetivo geral do artigo versa sobre a formação stricto sensu e as possíveis relações com a constituição e desenvolvimento da autonomia dos professores mestres e doutores que atuam na educação básica da rede pública do Distrito Federal. Os objetivos específicos são estabelecer possíveis relações entre formação stricto sensu e autonomia docente, e compreender como a autonomia modifica ou não o trabalho docente.

A fim de alcançar esses objetivos, o método de análise escolhido foi o materialismo histórico dialético, e os procedimentos de coleta de dados foram a entrevista semiestruturada e o questionário, tendo como sujeitos da pesquisa professores mestres e doutores que atuam na educação básica da rede pública do Distrito Federal.

\section{Referencial teórico}

A autonomia, compreendida aqui como independência intelectual capaz de propor transformações na realidade concreta por meio do coletivo (CONTRERAS, 2012), se vincula à possibilidade de compreender a realidade para além dos discursos imediatos, encontrando nas produções culturais e científicas, desenvolvidas pela humanidade ao longo da história, uma nova forma de ler o seu trabalho e sua atuação. Porém, trata-se de algo difícil de ser desenvolvido

\footnotetext{
${ }^{4}$ Cabe ressaltar que a pós-graduação da Pontifícia Universidade Católica do Rio de Janeiro (PUC-Rio) foi aprovada antes do parecer de regulamentação.
} 
quando se refere ao trabalho do professor, pois, diferentemente de outras atividades profissionais, a atual configuração do trabalho docente no capitalismo interfere diretamente na constituição de sua autonomia.

Proletarização e intensificação se retroalimentam no sucateamento do trabalho docente, no professor que precisa assumir uma alta carga de trabalho, e não possui, portanto, tempo para planejar suas aulas, realizar pesquisas, extensão entre outras atividades que não se constituem como “dar a sua aula”. Nesse prosseguimento, se incrementa a aceitação e dependência de esquemas préexistentes para a prática docente que, com a necessidade de facilitar o encaminhamento de sua atuação, diminui ou anula sua autonomia sobre seu trabalho. Uma autonomia que já, devido às condições de surgimento da atividade docente, nunca fora plena.

A autonomia dos professores exprime-se dentro de regras bastante definidas, que obrigam as ações profissionais a uma acomodação às situações reais. A liberdade do professor exerce-se, sobretudo, através da capacidade para se movimentar dentro de um quadro que só pode mudar parcialmente (SACRISTÁN, 1995, p. 72).

Fidalgo e Fidalgo (2009) trazem uma perspectiva mais complexa da questão sobre a intensificação do trabalho docente, que se movimenta no discurso de uma "pseudoautonomia”. Sob o título de um maior controle do seu trabalho, os professores são chamados a produzir e a tomar decisões em campos relacionados à problemática escolar, mas que extrapolam a função de ensinar.

É interessante perceber como os professores têm sido levados a assumir papéis que exigem cada vez mais, além de suas formações, na maioria das vezes, sem problematizar os condicionantes e os interesses que os impõem. [...] podem-se perceber docentes exercendo funções que mais os caracterizam como gestores de processos e de pessoas do que propriamente como professores, [...] tirando o caráter realmente educativo da profissão (FIDALGO; FIDALGO, 2009, p. 100).

Nesse processo, que pode ser considerado uma autointensificação, não raramente o professor "transfere para o próprio lar grande parte das responsabilidades, incumbências inadiáveis, prazos inexoráveis, avaliações decisivas” (FIDALGO; FIDALGO, 2009, p. 99). Ensinar fica para segundo plano e, ainda, como uma questão individual. O trabalho docente, propriamente dito, passa a ser quesito pessoal de cada professor. E essa forma de resolver por si as questões do seu trabalho, é confundida com a autonomia.

Desprestígio social e financeiro, proletarização, intensificação e suas consequências formam, assim, uma série de ataques ao trabalho docente, com o agravante de que não se trata apenas de promover a alienação e desumanização do trabalhador, mas de comprometer a realização do trabalho docente em sua dimensão ontológica. A falta de autonomia no trabalho docente, principalmente sobre o conhecimento a ser selecionado, transformado, transmitido, produzido, impede que o ato de ensinar algo a alguém (ROLDÃO, 2007) se realize. 
A desqualificação, a rotina, o controle burocrático, a dependência de um conhecimento alheio legitimado e a intensificação conduzem à perda da autonomia, perda que é em si mesma um processo de desumanização no trabalho. No entanto, no caso da educação, a reivindicação da autonomia não é apenas uma exigência trabalhista pelo bem dos funcionários. O é também pelo bem da própria educação (CONTRERAS, 2012, p. 212).

Desta forma, se torna claro que as contradições do trabalho no sistema capitalista são insustentáveis para a própria realização do trabalho docente. Contudo, embora em condições de trabalho burocratizada, normatizada e sucateada, a natureza do trabalho docente implica que, "no trabalho não material, a subsunção do trabalho ao capital apresenta limites, com o que se ampliam as possibilidades de resistência e de autonomia” (KUENZER; CALDAS, 2009, p. 24). Além disso:

O trabalho docente contém a contradição, a oposição entre o saber do dominante e o saber do dominado, em virtude da qual, ao executar a tarefa de construir conhecimentos, seja através do processo ensino-aprendizagem ou através da pesquisa, explicitam-se as condições sociais que determinam o caráter da exploração, e a falsa consciência pode ceder espaço à consciência mais totalizante (CURADO SILVA, 2011, p. 19).

Sendo assim, o trabalho dos professores pode se constituir como um elemento potencialmente subversivo, quando se foca na possibilidade e necessidade de o professor ter condições de transformar e conceber o objeto do seu trabalho - o conhecimento.

Portanto, trata-se de um tema que necessita ser amplamente discutido no âmbito da profissionalização docente, que diz sobre a questão da autonomia do professor sobre seu próprio trabalho - a autonomia profissional. Trazendo o foco para a constituição da profissionalidade docente, defende-se que é preciso construir, na formação, uma sólida base que sustenta o professor como profissional que define suas ações no âmbito da atividade docente. A autonomia do professor, neste sentido, se estrutura justamente sobre sua formação docente ao fornecer a fundamentação necessária para decidir os rumos de sua atividade.

A partir da autonomia do professor como profissional que estabelece o planejamento, realização e objetivo do seu trabalho, este poderia fazer pender sua atividade docente em direção à sua característica de formação humana em sua potencialidade ontológica emancipadora. Cabe à formação de professores, assim, construir uma autonomia docente que se dá pela apropriação de conhecimentos para o trabalho docente (LIMA, 2019).

Para desenvolver essa compreensão de autonomia é preciso, primeiramente, esclarecer que não se entende autonomia como um atributo pessoal vinculado à constituição de uma forte personalidade, como se é comumente difundido dentro do viés psicanalista. Procurando desmistificar o que seria realmente uma autonomia no trabalho docente, Contreras (2012) 
demonstra uma autonomia que não seria uma capacidade, um estado, ou atributo pessoal que os indivíduos possuem, mas um exercício, uma forma de se constituir pela maneira de se relacionar com os outros e com o mundo a sua volta.

Considera-se, ainda, que se trata também de uma forma de se relacionar com o próprio conhecimento. A autonomia docente se realiza, assim, no professor que exerce sua função como intelectual crítico, capaz de se comprometer com a defesa do bem comum em um processo coletivo dirigido às transformações da realidade a sua volta (CONTRERAS, 2012).

Nesse sentido, defende-se que a pesquisa na formação de professores não pode ser restringida à pesquisa aplicada, que considera uma problemática como especificidade de uma microrrealidade e, ainda, trazendo propostas de viés simplista e emergencial de solução a essa problemática. É necessário que o professor saiba fazer pesquisa no sentido estrito de ciência, e não se essa pesquisa terá utilidade no campo imediato da vida cotidiana.

Mesmo que a pesquisa científica que o professor se dedique não se volte à questão educacional, sendo, por exemplo, uma pesquisa na área de ciências biológicas, a relação com o conhecimento para este professor terá outra dimensão, que o conduz à autonomia intelectual. Participação em grupos de pesquisa, incentivo à produção acadêmica, discussão científicometodológica dos conteúdos do curso, publicações científicas devem fazer parte, portanto, da formação de professores.

Com esta autonomia intelectual sobre o conhecimento como seu objeto de trabalho, a partir do momento em que também se percebe como integrante da produção deste, é preciso promover a compreensão de como este objeto pode se desenvolver em sua prática profissional. Para isto, é necessário o contato crítico-historicizado acerca do desenvolvimento da educação até esta chegar à atual forma dominante de educação escolar, compreendendo este movimento a partir das transformações no modo de produção da vida social.

Portanto, faz-se necessário o estudo da totalidade social, suas contradições e as mediações presentes na escola, no estudante enquanto ser social concreto, no conhecimento escolar a ser transmitido, permitindo a compreensão de como o conhecimento pode interferir nos rumos sociais quando apropriado de forma revolucionária pela população. Como diz Curado Silva (2014, p. 20),

reafirmamos a posição de que a função do trabalho docente é ensinar, ou seja, proporcionar ao aluno a apropriação do conhecimento já produzido pela humanidade e as condições intelectuais para produzir novos conhecimentos e nova direção para a humanidade. Isso requer uma mediação que não é um dom artístico nem uma técnica, mas um saber profissional legitimado por conhecimentos conceituais e por uma visão historicizada desses conhecimentos, de si mesmo, da sociedade, de seus alunos e de sua profissão. 
A formação stricto sensu de professores da educação básica e a autonomia no trabalho docente: relações possíveis

Entende-se que esses conhecimentos conceituais sobre a questão do ensinar e do impacto que este tem na sociedade, seja de forma revolucionária ou conservadora, configura um fortalecimento da identidade docente, abrindo o caminho para a construção de sua autonomia profissional. E a autonomia profissional é elemento substancial para se reconfigurar sua atividade, problematizando a forma de se realizar o trabalho docente e direcionando este a uma atuação revolucionária ${ }^{5}$.

\section{A pesquisa}

Ao realizar o levantamento bibliográfico sobre a temática, primeiramente, no Banco de Teses e Dissertações da Coordenação de Aperfeiçoamento de Pessoal de Nível Superior (CAPES) ${ }^{6}$; no segundo momento, na biblioteca eletrônica Scielo - Scientific Electronic Library Online ${ }^{7}$ - que abrange uma coleção de periódicos científicos brasileiros, identificamos que a formação no mestrado/doutorado é bastante explorada no conjunto das pesquisas, principalmente nas últimas décadas, no entanto, poucas se voltam para o professor que atua na educação básica. O foco encontra-se na formação do professor universitário.

Todavia, é inegável que a preocupação com a formação dos professores se insere no movimento de valorização da atividade docente. Nas poucas pesquisas encontradas há um destaque aos impactos da formação no mestrado/doutorado quando abordam os avanços com a legislação; o objetivo em relação à educação básica; processos pedagógicos e conteúdo, ressaltando a necessidade de haver um formato específico para contribuir com a educação básica, trazendo alguns elementos interessantes para se pensar a formação de um mestre/doutor para a educação básica na perspectiva da autonomia.

Compreendendo que o indivíduo não pode ser analisado separado das suas condições materiais de vida e que a realidade é um todo inacabado, formado por contradições, a análise se realiza pelo método marxista - o materialismo histórico dialético, devido à necessidade em se compreender o objeto de forma ampla em suas relações com outros elementos que constituem a realidade.

A seleção dos sujeitos participantes da coleta de dados foi feita considerando a relação de cada um deles com o problema da pesquisa: o papel da autonomia na formação stricto sensu de professores da educação básica. São eles: os professores mestres e doutores da Secretaria de Estado de Educação do Distrito Federal (SEEDF).

${ }^{5}$ O conceito de atuação revolucionária é baseado em Lima (2019) tal perspectiva pode oferecer para o professor uma abertura de possibilidades de como agir subversivamente em seu trabalho, o que demanda uma capacidade analítica sobre as reais condições variantes de sua atividade e de perceber caminhos revolucionários que se ampliam ou se recuam de acordo com os movimentos da realidade concreta.

${ }^{6}$ Catálogo de Teses e Dissertações da Capes - Disponível em https://catalogodeteses.capes.gov.br/catalogo-teses/\#!/. Acesso em 22 jul. 2019.

${ }^{7}$ Scientific Electronic Library Online - SciELO. Disponível em:< https://www.scielo.org/>. Acesso em 22 jul. 2019. 
Segundo dados ${ }^{8}$ apresentados pela SEEDF em 2018:

1. O número total de professores em sala de aula em toda rede da SEEDFé 22.465;

2. O número total com mestrado é 770 (3,43\%);

3. O número total de professores com doutorado é 78 (0,35\%);

Os dados utilizados fazem parte de uma pesquisa mais ampla realizada por Barreiros (2013), que versou sobre Os sentidos e significados da formação stricto sensu no trabalho docente da educação básica. Foram entrevistados dez (10) sujeitos, ou seja, aproximadamente 20\% dos respondentes do questionário. Para a realização deste artigo parte dos dados foi atualizada, a fim de garantir a discussão proposta.

Investigar acerca da autonomia na pós-graduação stricto sensu diz respeito ao ato de pesquisar proporcionado por esse tipo de formação continuada. Os professores participantes da investigação reconhecem que a pesquisa tem um significado essencial no trabalho docente, mas as respostas são, por vezes, contraditórias.

Ao serem questionados sobre a compreensão do significado da pesquisa, relatam que o papel central da pesquisa é ser um elemento que proporciona autonomia intelectual e profissional, dados que indicam relação com a concepção de pesquisa no sentido estrito-ciência ${ }^{9}$. Destacam também a possibilidade de a pesquisa trazer mudanças da prática e como forma de atualização dos estudos. As falas abaixo são das entrevistas realizadas na pesquisa:

Na medida em que permite que eu tenha uma prática docente mais crítica e reflexiva. Possibilita-me também atuar com base em consistência teórica. Contribuo com a formação continuada de meus colegas nas discussões nos coletivos de trabalho. Dá-me mais segurança enquanto profissional e confere mais credibilidade a minha atuação, entre outros aspectos (Professor 5).

Pesquisei a formação de professores que ensinam matemática nos anos iniciais e isso me permitiu compreender melhor a organização do trabalho pedagógico como um todo. A pesquisa fortaleceu a minha compreensão do trabalho que é realizado nos anos iniciais (Professor 10).

Balança as estruturas dos professores, buscando tirá-los da letargia e se tornar agente ativo de seu trabalho, de modo que a pesquisa adentra a sala de aula e tem como alvo cada criança, algo tenho buscado fazer desde que conheci o construtivismo, e fui acompanhando os cursos de educação continuada em serviço, e cada vez mais tenho me imbuído de conhecimentos e indicadores para fundamentar minha práxis (Professor 39).

\footnotetext{
${ }^{8}$ Dados divulgados no sítio da Secretaria de Estado de Educação do Distrito Federal Relação percentual de docentes com formação de nível médio, licenciatura curta, licenciatura plena, especialização, mestrado e doutorado - Por CRE e escola. Disponível em: www.se.df.gov.br/dados-e-indicadores-eduacionais/ Acesso em 01 ago. 2019.

${ }^{9}$ Sentido estrito ciência se refere à pesquisa acadêmica vinculada à sua realização nas universidades, obedecendo a critérios rigorosos, próprios do campo científico. São entendidas aqui como atividades de estudo sistematizado realizado a partir do mestrado/doutorado.
} 
Há um predomínio da visão de que a pesquisa é um processo de reconstrução pessoal do conhecimento profissional e de sua prática. Isso ocorre pela predominância dessa tendência no campo de formação de professores. Vemos assim:

\begin{abstract}
A postura profissional é uma coisa que muda muito com a formação stricto sensu. Tanto a sua profissional com os alunos como com os próprios colegas. O seu olhar se torna muito mais crítico, muito, muito mesmo. Você consegue visualizar coisas, fatos que você antes não tinha olhos para isso, até mesmo no dia a dia da escola. Então você muda muito. Não tem como você não mudar sua postura profissional tanto com os alunos como com os colegas depois que você termina um curso no nível desse. Não tem como! (Professor 4).
\end{abstract}

Pesquisar ampliou os conhecimentos e a capacidade de leitura da realidade o que contribuiu sobremaneira para a mudança qualitativa em relação ao trabalho pedagógico desenvolvido com as crianças e também na possibilidade de diálogo com os pares. (Professor 54).

O discurso dos professores aponta que a pesquisa contribui com a formação do professor, independente de tratar diretamente da sua prática, até porque o fazem numa relação e compreensão ampla da relação teoria e prática. Estamos falando de construção de um processo emancipador de compreensão do seu fazer que inclui elementos práticos, teóricos, estéticos e políticos, e conforme Contreras (2012) ressalta, de constituir a autonomia do professor através da independência intelectual que trabalha na lógica do coletivo.

Há também os que acreditam que o fato de terem feito mestrado/doutorado não influencia e nem tem relação com a educação básica, como podemos ver na fala do Professor 3: “Eu, sinceramente, não vi vantagem em buscar a formação no mestrado e atuar na educação básica. Vi tanta coisa para além, que ficou muito distante da minha atuação.”

Para aproximadamente, 29\% dos sujeitos pesquisados, há um distanciamento em relação à docência. Os principais elementos que aparecem é que estudaram algo e trabalham em outra temática, outro nível de abstração e não existe aplicabilidade, pois são conteúdos complexos para esse nível de ensino. Vemos aqui um sujeito que passou pela formação stricto sensu e não considerou que essa faça diferença na atuação no nível da educação básica, como se esta fosse menos importante ou exigisse menos.

Diante disso, é possível inferir que pode ser que essa formação, de algum modo, não oportunizou momentos de reflexão, ou seja, uma pesquisa que fizesse com que ele desenvolvesse de forma mais ampla a questão da autonomia e entendimento da importância e oportunidade de formação das crianças nessa perspectiva.

Daí a importância de que esses sujeitos continuem participando do processo de pesquisa, a partir de grupos de pesquisa para que essa autonomia se desenvolva de modo mais amplo. Pois, 
como vimos anteriormente, mesmo que a pesquisa não se volte à questão educacional, sendo, por exemplo, uma pesquisa na área específica de uma disciplina, a relação com o conhecimento terá outra dimensão para este professor, dimensão essa que o conduz à autonomia intelectual. Acreditamos que outros fatores como a pouca importância dada aos professores pela sociedade, os baixos salários, a proletarização e intensificação atacam de tal modo o trabalho docente que aumentam as chances da continuidade de alienação.

Outros acreditam que o fato de se titular em uma área que não seja educação já revela que não há relação com o seu trabalho e que não há contribuição dessa formação stricto sensu. Fator que remonta ao fato de como o capitalismo enreda os sujeitos dificultando, algumas vezes, a constituição da autonomia. Esses aspectos podem ser observados nos relatos de alguns professores:

A pesquisa realizada não foi na área de educação e engloba conceitos que são de difícil compreensão para alunos do ensino fundamental (Professor 29).

Porque foram feitos estudos muito avançados que não são adequados a essa etapa de ensino. Os conhecimentos relacionados a área de pesquisa e aplicáveis no ensino fundamental não são necessariamente adquiridos apenas no mestrado. Um bom curso de graduação já possibilita a boa formação do professor para essa etapa (Professor 6).

Acho que o mundo acadêmico e a realidade da sala de aula, principalmente na Educação Básica são pontos contrastantes. Não creio que precisemos de mais e mais teóricos e sim de operacionais. (Professor 23).

Outro elemento que aparece, de certa forma paradoxal, é o sentimento de estranhamento entre os professores mestres/doutores na educação básica. Durante sua formação stricto sensu, eles eram vistos como pesquisadores temporários vinculados a algum programa. Já na escola há uma incompreensão dos motivos que fazem os sujeitos com tal formação de continuarem na educação básica, e por isso, algumas vezes, os diálogos passam a ser menores por algumas barreiras que são criadas.

Você volta para a escola repensada, mas a escola não repensou nada. Então você é chutado para lá e para cá. Me sentia deslocada. Um descaso. (...). As pessoas continuam amassando o mesmo barro, andando no mesmo caminho, fazendo as mesmas coisas, acontecem os mesmos problemas... aí na hora de um problema grave, para todo mundo para se assustar, mas refletir, chamar alguém para fazer uma palestra, fazer uma oficina, estudar ou refletir, debater sobre aquilo ninguém faz. Nem aqui e nem em outras escolas (Professor 13).

Eu caí na besteira de falar sobre a minha titulação. Aí a outra professora falou: Não, mas aqui eu conheço muito. E eu disse: Mas eu também conheço muito. Eu dava palestra no Brasil inteiro, eu era metida em tudo quanto era coisa. Agora que eu sosseguei. Eu quero estar aqui com os meus projetos. Eu tenho muito orgulho de mim, eu era uma guerreira. Aí eu fui muito mal aceita na escola. Eu podendo contribuir na escola, mas estava abafada, não tinha vez. Eu querer falar sobre inclusão na reunião e ninguém dar a mínima. Aí quando resolvi falar e depois de todo mundo sabotar, sabotar intencionalmente, tipo pra eu chegar ao ponto de pedir pra sair, como uma prova de resistência (Professora 14). 
Ao retornar da minha licença senti muita falta de estudar. A sensação que tenho é que somos engolidas pelo cotidiano, o que nos impede de dedicar um tempo para estar em contato com outras pesquisas, com a construção do conhecimento propriamente dita. (Professora 54)

Esses relatos demonstram o movimento de sentir-se estranho no exercício da função na educação básica, ao regressar após conclusão do mestrado/doutorado, e são aspectos que parecem estar relacionados à busca de formação para a pesquisa fora do âmbito escolar. O que ocorre é uma espécie de ruptura com algumas visões e papéis predominantes no senso comum referentes à educação básica e também certa cobrança dos colegas os responsabilizando no que tange à solução de problemas gerais da escola. O professor se sente deslocado e não se reconhece na cultura escolar e nem se identifica com alguns colegas. Há, assim, a necessidade de promover a relação entre os estudos e a prática profissional.

A falta de autonomia para esse cenário pode ser um elemento que justifica tal estranhamento, pois a transformação do professor que teve a oportunidade de passar pela formação stricto sensu não é a mesma vivida por quem ficou imerso no cotidiano da educação básica. Por isso a importância da busca por aproximação entre Universidade e Escola na promoção da pesquisa, produção do conhecimento que poderia acontecer de maneira coletiva, a partir de grupos de estudos e pesquisa, por exemplo.

Os dados demonstram a necessidade de o professor participar de grupos de pesquisa para dar continuidade a tal atividade, evidenciando, mais uma vez, que a pesquisa não pode ser uma atividade isolada. Porém os grupos e/ou processos de formação ocorrem fora da escola.

Nesse sentido, inferimos que 79\% dos docentes, após a conclusão da formação stricto sensu, ingressam em grupos de pesquisa. A maioria desses grupos são da Universidade de Brasília - UnB a saber: Grupo Compasso que pesquisa a história da matemática escolar no DF; GPCULT/ psicologia UnB; Grupo de pesquisa sobre os conselhos municipais de educação; Grupo de sistematização do Programa de Avaliação Seriada da UnB; Grupo de pesquisa Recepção e práticas de leitura na UnB; Grupo de estudo e pesquisa sobre avaliação na UnB. Outros grupos se constituem por parcerias entre a Secretaria e a UnB, como Grupo de Pesquisa em Tecnologias da Educação. E reuniões de iniciativa própria em que um pequeno grupo se reúne para desenvolver trabalhos científicos para publicação em revistas especializadas.

Dessa forma, apontamos a necessidade de que haja uma discussão política da formação de professores no mestrado/doutorado, considerando essa questão no plano de carreira, dando condições reais para isso, e não somente uma discussão epistemológica do professor reflexivo. O que queremos dizer é que junto com a discussão epistemológica e a formação é necessário criar 
políticas de pesquisa e discutir condições da carreira docente e as condições materiais da escola, ou seja, pensar na profissionalização e profissionalidade do docente.

Ao viver o conflito de condições de trabalho, condições de pesquisa, relacionamento e identificação, os professores declaram haver demanda por pesquisa no cotidiano da educação básica. Entretanto, explicam que acabam por ter apenas estratégias pedagógicas ou atitude reflexiva devido à dificuldade de pesquisar no sentido mais acadêmico, consequência das condições de trabalho e falta de políticas públicas voltadas para a área.

O que observamos é que não há aproveitamento e apropriação, por parte da SEEDF, do que a pesquisa no sentido estrito-ciência realizada por esses mestres e doutores pode contribuir. Não há ações e muito menos políticas de/para pesquisas constituídas nas redes de ensino, embora haja profissionais com formação para desempenhar essa atividade.

Por tudo que já estudei e acumulei (...) eu acho que a Secretaria não reconhece o nosso estudo. Eu acho que a gente com essa bagagem, a gente deveria sim ir para uma coordenação de cursos e núcleos (Professora 48).

Quando retornei da licença, tinha um grande desejo de compartilhar sobre minha pesquisa e os achados da mesma com os meus colegas de trabalho, porém só consegui fazer isso na escola em que atuava. Em outros espaços encontrei resistência (Professora 54).

Os educadores acabam se sentindo isolados, sem o aporte adequado das políticas educacionais. Dessa forma, torna-se cada vez mais difícil e contraditório discutir a formação e atuação de professores pesquisadores, uma vez que as teorias não se preocupam em discutir políticas públicas para sua efetivação.

Destarte, os dados acima indicam que o desenvolvimento da autonomia está diretamente atrelado ao trabalho docente e que a formação via pesquisa seja ela stricto sensu ou em grupos de pesquisa são molas propulsoras desse fator.

\section{Considerações finais}

Formar e ser professor é uma tarefa complexa e não será através de fórmulas, ou medidas simplistas que iremos resolver diretamente os atuais problemas da escola e do sistema educacional. A questão é entender como podemos enfrentar de maneira coletiva, os problemas que invadem o dia a dia da escola, ou seja, como criar condições de trabalho que podem garantir a possibilidade de transformar em prática o discurso de transformação da escola.

Essa possibilidade pode ser representada e exemplificada através dos professores que apostam na resistência e realizaram uma pesquisa no sentido estrito-ciência nos cursos de pós-graduação, o 
que confirma a certeza de que essa atividade é possível e colabora na formação de professores, apesar de algumas contradições apresentadas. Dessa forma, a pesquisa precisa ser pensada e implementada como uma política de trabalho instituída e amparada no plano de carreira, com condições de ser desenvolvida.

O trabalho docente é aqui compreendido como forma de trabalho não-material que se articula ao saber produzido pelos homens, histórica e de forma coletiva, na (re)produção das condições materiais da sua existência. Assim, ele exige por sua própria natureza, que o profissional da educação esteja em constante processo de atualização, por esta razão, como vimos, em alguns estudos, muitas vezes, procura-se esta formação stricto sensu. Mas, é interessante pensar na contribuição dessa formação para a atuação do professor; as razões para buscá-la; as mudanças provocadas por ela; e as possíveis aspirações que a mesma provoca.

Quando se busca o desenvolvimento da autonomia docente, se entende que a formação stricto sensu deve ser pensada de modo a permitir uma formação de professores capazes de se relacionar com o conhecimento, enquanto o objeto de sua atividade, de forma crítica e criativa. Em outras palavras, o professor necessita de uma formação que o permita se apropriar do conhecimento de forma que este saiba também o produzir, além de uma fundamentada compreensão sobre a questão da escola, sociedade, trabalho, política, cultura, com a consciência de sua função profissional.

Dessa forma, se defende que o professor necessita ser capaz de definir o que ensinar, como ensinar e porque ensinar, compreendendo sua função no processo de formação da humanidade nos indivíduos. Consideramos que, algumas vezes, a formação stricto sensu não é suficiente para garantir essa clareza, como vimos no relato de alguns docentes durante a pesquisa, mas na maioria, sim.

Nesse sentido, a autonomia no trabalho docente é de caráter epistemológico, sendo essa uma pertinente via para se contrapor às atuais investidas de controle externo do trabalho docente. Sendo assim, o professor necessita de uma formação que o permita se apropriar do conhecimento de forma que este saiba também o produzir, ou seja, uma formação para a pesquisa.

Esses fatores levam à defesa da necessidade que os cursos de mestrado e doutorado forneçam instrumentos que possibilitem a reflexão aprofundada sobre a prática pedagógica e sua articulação com a prática social mais ampla, pois pode possibilitar maior autonomia ao professor para lidar com os problemas que surgem das condições objetivas, repercutindo diretamente no trabalho pedagógico do professor, para que o mesmo não se sinta isolado e incapaz de dar respostas aos dilemas da sua prática profissional e aos dilemas da educação. 
As práticas escolares assumidas pelos professores mestres/doutores, relatadas na pesquisa, caminham na direção da construção de uma relação mais consciente com o trabalho e as suas finalidades sociais. A pesquisa acaba se tornando um ato de resistência, mas ela não deve ser feita individualmente, é preciso investir em políticas e na profissionalização docente.

A formação strictu sensu, ao possibilitar a realização de pesquisa aos professores mestres e doutores, permitiu aos sujeitos desenvolver capacidade de análise e investigação, o que os deixou, em sua maioria, aptos a formar sujeitos no espírito crítico, na dúvida metódica e na busca da unidade teoria e prática, possibilitando a práxis. Considerando que, segundo Moura e Paula (2013), o papel da pós-graduação na produção da pesquisa e na formação de pesquisadores se volta para o avanço do conhecimento científico, criativo, crítico, novo e relevante, há, nesta atividade, a possibilidade de formar sujeitos autônomos, capazes de dizer não e tomar as próprias decisões, processos imprescindíveis para o exercício da docência.

Contudo, por ainda termos números incipientes de docentes com mestrado e doutorado na educação básica, identificamos um terceiro elemento que incide sobre o trabalho docente, a questão do estranhamento por parte dos pares e do próprio professor. O fator do estranhamento nos faz refletir sobre a seguinte questão: os professores que voltam do mestrado/doutorado tiveram a oportunidade de desenvolver certa autonomia, no entanto, voltam para um lugar em que está muito parecido com o que ele deixou. Ele retorna outro, mas o local e as pessoas que ali estão não passaram pela mesma transformação.

Na educação básica não existe meios tão diretos para o desenvolvimento da autonomia, como os proporcionados pela universidade a partir da formação stricto sensu. Por isso, é preciso investimento na participação em grupos de pesquisa, incentivo à produção acadêmica, discussão científico-metodológica dos conteúdos do curso, publicações científicas, portanto, fazendo parte da formação de professores.

Retomando o objetivo geral acerca da formação stricto sensu e as possíveis relações com a constituição e desenvolvimento da autonomia dos professores mestres e doutores que atuam na educação básica da rede pública do Distrito Federal fica claro que existe o desenvolvimento na maioria dos sujeitos que passam por essa formação. Essas relações versam sobre a forma de perceber o trabalho, a importância da pesquisa como promotora de conhecimento e autonomia e uma modificação do trabalho docente à medida que esses mestres e doutores têm o potencial de promover educação emancipadora. 
As implicações educacionais deste estudo são a de incentivo às políticas públicas de formação stricto sensu aos professores de educação básica, a fim de possibilitar o aumento de professores que realizam essa formação; a necessidade de que as redes de educação criem espaços de divulgação e diálogos sobre as pesquisas realizadas; a urgência em pensar meios mais efetivos de aproximação com as escolas de educação básica com o objetivo de disseminar conhecimento, aproximar teoria e prática e que o desenvolvimento e ampliação da autonomia via pesquisa, proporcionada pela formação stricto sensu, deve ser ampliada a partir de um pressuposto que considera a educação em um viés emancipador.

\section{Referências}

BARREIROS, D. K. Os sentidos e significados da formação stricto sensu no trabalho docente da educação básica. 2013. 135f. Dissertação (Mestrado em Educação) - Faculdade de Educação, UnB, Brasília.

BRASIL. Ministério da Educação. Coordenação de Aperfeiçoamento de Pessoal de Nível Superior. Plataforma Sucupira. $2017 . \quad$ Disponível em: $<$ https://sucupira.capes.gov.br/sucupira/public/consultas/coleta/programa/quantitativos/quantitativoAreaConhecimento.jsf?areaAvaliacao=38>. Acesso em: 02 jul. 2019.

BRASIL. Instituto Nacional de Estudos e Pesquisas Educacionais Anísio Teixeira. Relatório do $2^{\circ}$ Ciclo de Monitoramento das Metas do Plano Nacional de Educação - 2018. - Brasília, DF: Inep, 2018. Disponível em: http://portal.inep.gov.br/documents/186968/485745/RELAT\%C3\%93RIO+DO+SEGUNDO+CICLO+DE+MONITORAMENTO+DAS+METAS+DO+PNE+2018/9a039877-34a5-4e6a-bcfd-ce93 936d7e60?version=1.17> Acesso em 06 de jul. 2019.

Conselho Federal de Educação (CFE). Câmara de Educação Superior (SESU). Parecer, $n$. 977, de 03 de dezembro de 1965. Brasília, 1965. Disponível em: <https://www.capes.gov.br/images/stories/download/legislacao/Parecer_CESU_977_1965.pdf>. Acesso em: 06 jul. 2019.

. Ministério da Educação. Coordenação de Aperfeiçoamento de Pessoal de Nível Superior. GEOCAPES. 2017. Brasília [s.d]. Disponível em: <https://geocapes.capes.gov.br/geocapes/> Acesso em 01 de jul. 2019.

CAMPOREZ, Patrick. Expansão do ensino superior nos governos passados foi uma tragédia afirma ministro da educação. O Globo. Publicado em 07 de maio de 2019. Disponível em: < https://oglobo.globo.com/sociedade/expansao-do-ensino-superior-nos-governos-passados-foi-umatragedia-afirma-ministro-da-educacao-23647233> Acesso em: 10 de abril de 2019.

CONTRERAS, José. A autonomia de professores. São Paulo: Cortez, 2012.

CURADO SILVA, K. A. P. C. da. A formação de professores para a educação integral na escola de tempo integral: impasses e desafios. In: ROSA, Sandra Valéria Limonta et al (Orgs.). Educação integral e escola pública de tempo integral: formação de professores, currículo e trabalho pedagógico. Goiânia: América, p. 15-32, 2014. 
A formação de professores na perspectiva crítico-emancipadora. Linhas Críticas. Brasília, v. 17, n.32, p. 13-31, jan./abr. 2011.

FIDALGO, Nara Luciene Rocha; FIDALGO, Fernando. Trabalho docente e a lógica produtivista: conformação e subjetividade. In: OLIVEIRA, Maria Auxiliadora M. e FIDALGO, Nara Luciene R. (Orgs.). A intensificação do trabalho docente: tecnologias e produtividade. Campinas, SP: Papirus, 2009. p. 91-112

KUENZER, Acácia Z.; CALDAS, Andrea. Trabalho docente: comprometimento e resistência. In: FIDALGO, Fernando; OLIVEIRA, Maria Auxiliadora M.; FIDALGO, Nara Luciene R. (Orgs.). A intensificação do trabalho docente: tecnologias e produtividade. Campinas-SP: Papirus, 2009. p. 19-48.

LIMA, Fernanda Bartoly Gonçalves de. Emancipação humana e educação escolar: perspectivas para a formação de professores. 2019. 350 f., il. Tese (Doutorado em Educação)-Universidade de Brasília, Brasília, 2019.

MOURA, E. M; PAULA, F. V. A pós-graduação e o estudo das relações entre habilidades metalinguísticas e linguagem escrita. Estudos e Pesquisas em Psicologia. 2013. Disponível em:< http://www.redalyc.org/articulo.oa?id=451844511006> Acesso em 22 jul.2019.

ROLDÃO, Maria do Céu. Função docente: natureza e construção do conhecimento profissional. In: Revista Brasileira de Educação. V. 12, n.34 jan/abr. 2007.

SACRISTÁN, J. Gimeno. Consciência e ação sobre a prática como libertação profissional dos professores. In: NÓVOA, António (org.). Profissão Professor. Porto, Portugal: Porto Editora, 1995. p.63-92. 